Article

\title{
Artificial Intelligence in the Water-Energy-Food Model: A Holistic Approach towards Sustainable Development Goals
}

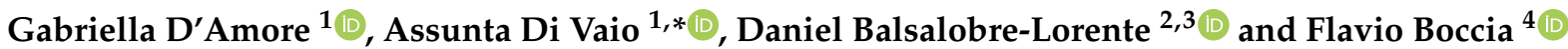 \\ 1 Department of Law, University of Naples "Parthenope", Via G. Parisi, 13, 80132 Naples, Italy; \\ gabriella.damore@uniparthenope.it \\ 2 Department of Political Economy and Public Finance, Economics and Business Statistics and Economic Policy, \\ University of Castilla-La Mancha, C/Altagracia, 50, 13071 Ciudad Real, Spain; daniel.balsalobre@uclm.es \\ 3 Department of Applied Economics, University of Alicante, Carretera San Vicente del Raspeig s/n, \\ 03690 San Vicente del Raspeig, Spain \\ 4 Department of Economic and Legal Studies, University of Naples "Parthenope", Via G. Parisi, 13, \\ 80132 Naples, Italy; flavio.boccia@uniparthenope.it \\ * Correspondence: susy.divaio@uniparthenope.it; Tel.: +39-0815474135
}

check for

updates

Citation: D'Amore, G.; Di Vaio, A.; Balsalobre-Lorente, D.; Boccia, F. Artificial Intelligence in the Water-Energy-Food Model: A Holistic Approach towards Sustainable Development Goals. Sustainability 2022, 14, 867. https://doi.org/10.3390/ su14020867

Academic Editor: Muhammad Ikram

Received: 11 December 2021

Accepted: 11 January 2022

Published: 13 January 2022

Publisher's Note: MDPI stays neutral with regard to jurisdictional claims in published maps and institutional affiliations.

Copyright: (C) 2022 by the authors. Licensee MDPI, Basel, Switzerland. This article is an open access article distributed under the terms and conditions of the Creative Commons Attribution (CC BY) license (https:// creativecommons.org/licenses/by/ $4.0 /)$.

\begin{abstract}
This study aims to analyze the role of artificial intelligence (AI) in the Water-Energy-Food (WEF) nexus under the lens of institutional, stakeholder, and innovation theories. Specifically, this study focuses on AI as the technology adopted by companies to promote Sustainable Development Goals (SDGs). A structured literature review has been conducted on 94 articles published from 1990 to 2021 in ISI Web of Science, Scopus, and Google Scholar. This study develops an in-depth review of the literature on the main articles arguing about these issues. The findings highlight the increasing relevance of $\mathrm{AI}$ in the water, energy, and food industries individually considered, but the study of $\mathrm{AI}$ as a connector between water, energy, and food to achieve SDGs is still under investigation. Research on AI for WEF nexus management has adopted mostly a technical perspective, neglecting the relevance of management tools and the business model concept. Most of the articles did not adopt a specific theoretical lens, but scholars recognize the need to adopt a multi-stakeholder approach and the important role played by AI and other digital technologies to address the WEF nexus challenge. This study proposes an integrated approach for managing the nexus through AI technologies to meet sustainable and responsible business models. The gap between research and policy making could be filled by combining scientific data and policy needs with inclusive tools that are technically viable for sustainable resource utilization.
\end{abstract}

Keywords: artificial intelligence (AI); Water-Energy-Food (WEF) nexus; business models; Sustainable Development Goals (SDGs); institutional; stakeholder; innovation theories; structured literature review (SLR)

\section{Introduction}

Over the past two decades, scholars and practitioners have been paying increasing attention to the concept of Water-Energy-Food (WEF). This process has tried to become a nexus for the "right way" to optimize the use of natural resources, promoting environmental sustainability goals [1-3]. The WEF nexus concept originates from the international discussion on sustainable development during the World Economic Forum in 2011, used to describe the interconnections and interdependencies among water, food, and energy sectors [4]. Water is needed to generate energy and grow food; energy is required for water supply and produces food; and food can generate energy, reducing waste [5]. This means that any issue in managing one of these resources can affect the others, and each resource can benefit from the synergies coming from an integrated approach to their use.

Conceived as a tool "to promote policy coherence through identifying optimal policy mixes and governance arrangements across the water, energy and food sectors" ([6], p. 165), 
the WEF nexus has gained prominence after the adoption of the UN 2030 Agenda in 2015 for handling the sustainable development goal (SDG) interconnections, specifically for SDG\#2 (zero hunger), SDG\#6 (clean water and sanitation), and SDG\#7 (affordable and clean energy) $[7,8]$. According to Le Blanc [9], the successful achievement of the UN 2030 Agenda needs to consider the potential trade-offs and synergies among several SDGs. Indeed, the UN 2030 Agenda footprint recognizes in its conceptualization the existence of interconnections among targets to achieve the SDGs, which require the implementation of coherent policies and solutions across different actors and sectors [10]. Despite the great efforts of academia concerning these issues, there has not been much progress in developing and adopting coherent policies and tools to handle SDGs' interlinkages [7,11,12]. The literature on the WEF approach has highlighted the existence of several constraints to its implementation to meet SDGs, such as rigid frameworks, entrenched interests, planning and implementation procedures, and a lack of information tools capable of supporting decision-making processes $[7,8,12]$. Scholars agree on the need to establish coordination and cooperation mechanisms applicable to support institutions and governments in the definition of policy goals and actions for leading to the desired outcomes. However, they struggle to provide insights on the conditions, dynamics, and factors that enable cross-sector coordination and collaboration [6].

Recent studies [12-14] found sustainability goals and sustainable performance cannot be achieved without innovations. The overlapping of data and information, the lack of adequate knowledge of human resources, and the unpredictability of climate events could severely affect decision-making processes, leading to sub-optimal solutions and slowing down the sustainability agenda. Artificial intelligence (AI) technologies can process large amounts of data, reveal information that otherwise would remain hidden, and solve complex problems. Yet, the contribution of AI is not limited to data processing. Still, it has the potential to identify science-based solutions for environmental and climate degradation problems that are not biased by specific individual or groups interests [13], supporting multi-stakeholder decision-making processes towards sustainability. AI can help the multiple players involved in the water, energy, and food industries to meet the UN 2030 Agenda.

Some scholars [15-17] have highlighted how AI is able to change not only the way to generate and use information for decision making [18], but also the ways of doing business from a sustainable and socially responsible perspective [19,20]. Caprani [21] (p. 103) highlights the significant role of business in achieving global transformational development, but this has been almost entirely ignored by the literature on the WEF that has focused mostly on the other stakeholders (e.g., governments and community). Moreover, while some scholars have highlighted the relevance of digital technologies in the water, energy, and food sectors $[15,17,22,23]$, the potential role of AI for the management of the WEF nexus has been underestimated, as has its contribution to the governance of multiple interactions among the resources, sectors, and institutions involved.

This study aims to fill this gap by analyzing AI as a key tool for managing WEF nexus interdependencies, supporting the multi-stakeholder dialogue and decision-making processes. AI can support companies in defining sustainable business models, including the concept of the WEF nexus. The aim of this study is also to highlight the direct interconnections existing between the three dimensions—food, water, and energy—on which it is necessary to reflect to implement adequate policy and governance actions, so as not to limit itself to the simplest consideration of two-by-two relationships as done by previous studies.

Starting from an in-depth structured literature review (SLR) under the lens of institutional, stakeholder, and innovation theories, we try to bridge the research gap by answering the following research question (RQ): What is the role of $\mathrm{AI}$ in the WEF business models for the achievement of SDGs?

Our analysis focused on a collection of data composed of 94 articles extrapolated from ISI Web of Science (WoS), Scopus, and Google Scholar (GS) published from 1990 to 2021. The findings evidence the significance of AI for sustainable business model challenges and 
the main factors useful to achieve WEF business models. Research on AI for sustainability has mostly adopted a technical perspective, lacking evidence of the cultural drift it is able to generate, transforming traditional businesses into sustainable ones. In terms of originality, this study proposes a holistic approach to managing the "nexus" of the water, energy, and food industries through AI to achieve sustainable, responsible, and predictive business models, that is, the goals of the UN 2030 Agenda. Furthermore, it also suggests extending research to social and economic measures and considering $\mathrm{AI}$ in its complexity, also considering adverse effects. AI success strongly depends on education, training, context, government policies, financial resources, and cultural variables, which have been ignored in most studies.

The remainder of the study is organized as follows. Section 2 provides the theoretical framework underlying this study. Section 3 describes the methodology used for the analysis. Section 4 highlights the results. Section 5 includes the discussion and the main theoretical implications. Section 6 contains the conclusions, limitations, and future research perspectives.

\section{Theoretical Background}

Over the past two decades, scholars have used the WEF approach as a multidimensional tool to describe the complexity of human-environment interactions, finding several interpretations and applications [10]. Scholars agree in the belief that the WEF nexus approach requires the establishment of strong cross-sectoral boundary coordination of policies, governance, and managerial tools, whose complexity justifies, at least partially, their slow implementation $[6-8,12,23,24]$. Indeed, the complexity of the nexus is due to the interaction of environmental resources, the intersection of multiple interests (e.g., government, private sector, and society), and the distribution of environmental and institutional risks, reflected in the incidence, frequency, and duration of natural hazards and in the resilient capacities of institutions to predict and cope with the risks [8]. The governance of the WEF nexus requires the establishment of coordination mechanisms among stakeholders (e.g., state, private sector, and civil society), sectors (e.g., water, energy, and food), and scales (e.g., political/administrative, ecological, and technical). Water, energy, and food follow different regulations and are administered by different government levels, and these make the establishment of coordinated policies and governance particularly complex.

However, studies focus almost exclusively on identifying environmental resource interactions, proposing alternative technical solutions to optimize their use, such as reducing the water and energy consumption from producing food. These solutions must consider the context in which they are implemented, considering the strong context-dependence of water, energy, and food security. This means that any solution cannot be detached from the analysis of the context [25]. Institutional theory [26] sustains the need for institutions to adapt to the external environment to survive. As several scholars have evidenced [27-30], WEF nexus implementation is grounded not only in the institutional capacity to coordinate and establish the right policies, strategies, and solutions, but also in the firms' willingness to address the sustainability challenge and household/society engagement by adopting a multi-stakeholder approach.

The role played by the business for translating WEF principles on the ground was already highlighted during the World Economic Forum [31] (p. 3): "Accelerating the involvement of the private sector through making the business case for sustainability and the WEF nexus is essential for driving change and getting to scale". Nevertheless, studies on how multi-stakeholder interests involved in the WEF nexus can converge have found little space in the literature on the WEF nexus. The management of interconnections between water, energy, and food resources requires a holistic understanding of the multiple interests involved. In this regard, according to stakeholder theory [32], value creation in businesses, as well as in all types of organizations, depends on their ability to satisfy the interests of all groups that have a stake in the activities that make up the business, managing the conflicts and potential trade-offs that come from the relationships among 
the actors [33]. The engagement of all stakeholders involved in the WEF nexus towards achieving environmental sustainability and, specifically, the UN 2030 goals is far from a simple issue.

Studies about the barriers to adopting the WEF approach have not been followed by the development of managerial tools to capture the interconnections and interdependencies among SDGs, especially to support the decision-making processes of the business. Albrecht et al. [12] (p. 4) state that "Methods have largely been borrowed or adapted from conventional disciplinary approaches, e.g., efficiency analysis based on engineering process studies, economical supply chain and commodity-chain analyses, and agronomic soil-plan-water assessment". Stakeholder engagement may be carried out to different levels: information sharing, consultation, consensus building, decision making, and partnership. A lack of data and low levels of communication reduce the willingness to collaborate and the propensity to invest in new projects and assume the related risks $[34,35]$.

The overlapping of data and information, the lack of adequate knowledge of human resources, and the unpredictability of climate events could severely affect decision-making processes, leading to sub-optimal solutions and slowing down the sustainability agenda. These have brought about the development of digital technologies in the last decade, such as IoT, big data, and AI.

The term AI is used to define machines' abilities to display human skills such as reasoning, learning, and planning to solve problems. This is possible thanks to machine learning (ML) models and algorithms, capable of analyzing and learning from large amounts of data that computers receive from external sensors, such as video cameras, satellites, and so forth. AI can correctly interpret external data and use the information to reach specific goals and activities by a flexible configuration [36]. "The interaction between AI and human intelligence is based on algorithms that could help managers to make the right decisions, generating a cultural drift in which a large number of data, connection and interaction become part of the standard management and organization" [16] (pp. 19, 284). Kahnemna et al. [37] highlighted how these algorithms are able to assume more efficient decisions than humans can take. For this reason, it appears particularly suitable to be employed as a tool to support complex decision processes [18] such as those required by the WEF nexus.

In more detail, according to the innovation theory, digital technologies favor the collaborative acquisition of information and the sharing of knowledge [38]. AI can allow a holistic understanding of the potential consequences of policies, technologies, and environmental practices [8]. The new possibilities unlocked by the I4.0 technologies can help businesses to address several SDGs [39]. AI represents a tool to manage information in sustainable business models, allowing the business to address the UN 2030 Agenda goals. Its contribution to the sustainability challenge led to a vast application of AI technologies in many industries to reduce natural resource uses.

Several studies $[14,16,17,40,41]$ have fostered the application of AI to address sustainability challenges. ML models have been increasingly used in the water sector for predicting and optimizing water resource use in the energy sector to support forecasting and decision making on energy planning, production, distribution, maintenance, and agriculture for weather prediction, fertilizers, irrigation optimizations, and so on. More sophisticated software and digital technologies are needed as systems become more complicated. One of these consists of the virtual reproduction of physical products that provide a real-time snapshot of their status, called digital twins, that, thanks to AI algorithms, can predict the future performance of physical assets without intervening in the product. Digital twins have found application in the water, energy, and agriculture sectors, enabling users to assume decisions without being present, saving time and costs and improving sustainability.

The main advantages recognized by research on AI for sustainability are the higher data accuracy and information transparency, the cost and time efficiency, the availability of science-based solutions not biased by self-group interests, and the increased predictability of future scenarios that enhance system resilience to climate changes. In particular, [15] highlighted how AI has changed the way to make decisions and "revolutionized the ways 
of doing business", influencing management practices and business models to meet SDGs. The business model consists of "a representation of how a related set of decision variables in the area of business strategy, architecture and economics are addressed to create a sustainable competitive advantage in defined markets" [42]. Technological innovation can influence business management and practices, creating the condition for reducing the cost and increasing the value, combining profit interest with sustainability goals [43]. Other scholars $[14,16,17,40,44,45]$ have highlighted how the adoption of AI by firms, as well as through partnerships with other companies, can give a decisive boost to the UN 2030 Agenda. Nevertheless, AI can also negatively affect SDGs, considering that some aspects can increase social inequalities if not correctly addressed. Moreover, the electronic equipment needed to elaborate all data required needs to be disposed of at the end of its life cycle, raising questions about their impact on the environment. All these doubts are still waiting for an answer from international organizations called upon to ensure progress without increasing disparities among populations [46].

\section{Methodology}

We adopted a qualitative approach to conducting an SLR on AI issues, business models, the WEF nexus, and the WEF nexus in water, energy, and food industries meeting SDGs. We use SLR analysis to uncover emerging trends in article and journal outcomes and explore the extant literature's intellectual domain. This allows us to reply to our $\mathrm{RQ}$ and define the research agenda for the future tendencies about the issues proposed in this study. Otherwise, the literature review as a research methodology allows for providing an overview of fields in which the research is still a patchwork and, above all, interdisciplinary [47]. The qualitative approach allowed us to choose the technique of content analysis of articles included in our data collection to identify, investigate, and report patterns in the form of topics proposed within our study $[47,48]$.

\subsection{Survey Design}

The survey design of this study is composed of four steps. The first step is to build a database from WoS, Scopus, and GS. The second step is to identify relevant articles. The third step is to track citations for additional pertinent articles manually. The fourth step is composed of four sub-phases. More precisely, it includes: (1) extraction of articles from databases; (2) identification of significant articles; (3) localization of highly cited articles; and (4) identification of other significant articles published on the issues proposed in this study.

\subsection{Scientific Databases}

We collected documents through WoS, which allows subscription-based access to multiple databases of many different academic disciplines. We selected the WoS database since it is one of the most used in socio-economic disciplines. Its contents are comparable in size to Scopus [49], although it requires fewer data cleaning operations [50]. However, to avoid missing relevant articles, we launched the same search on the Scopus database. We cross-checked the references obtained from the two databases, eliminating all duplicates. This freely accessible web search engine indexes the articles of the scholarly literature of many research fields.

Following the protocol adopted in a previous article in Sustainability [16], our research design is structured in two main phases, as shown in Figure 1. In the first phase, we launched several searches in WoS through the truncated association of three groups of strings:

- String1: water energy and food AND artificial intelligence;

- String2: water energy and food AND business model*;

- String3: water energy and food AND sustainable development goal*. 
Document type: articles in WoS and Scopus

Indexed journals in English

Timespan: 1990 up to 2021

Search strategy: TOPIC by using truncated combinations of five groups of search strings

String1: water energy food AND artificial intelligence

String2: water energy food AND business model*

String3: water energy food AND sustainable development goal*
String1: 49 article (WOS and Scopus)

String2: 87 articles (WOS and Scopus)

String3: 493 articles (WOS and Scopus)

\section{Identification process}

- Reading of abstract and full paper

- Involvement of four authors

- Inclusion criteria: if the aim of the paper was related to our RQ

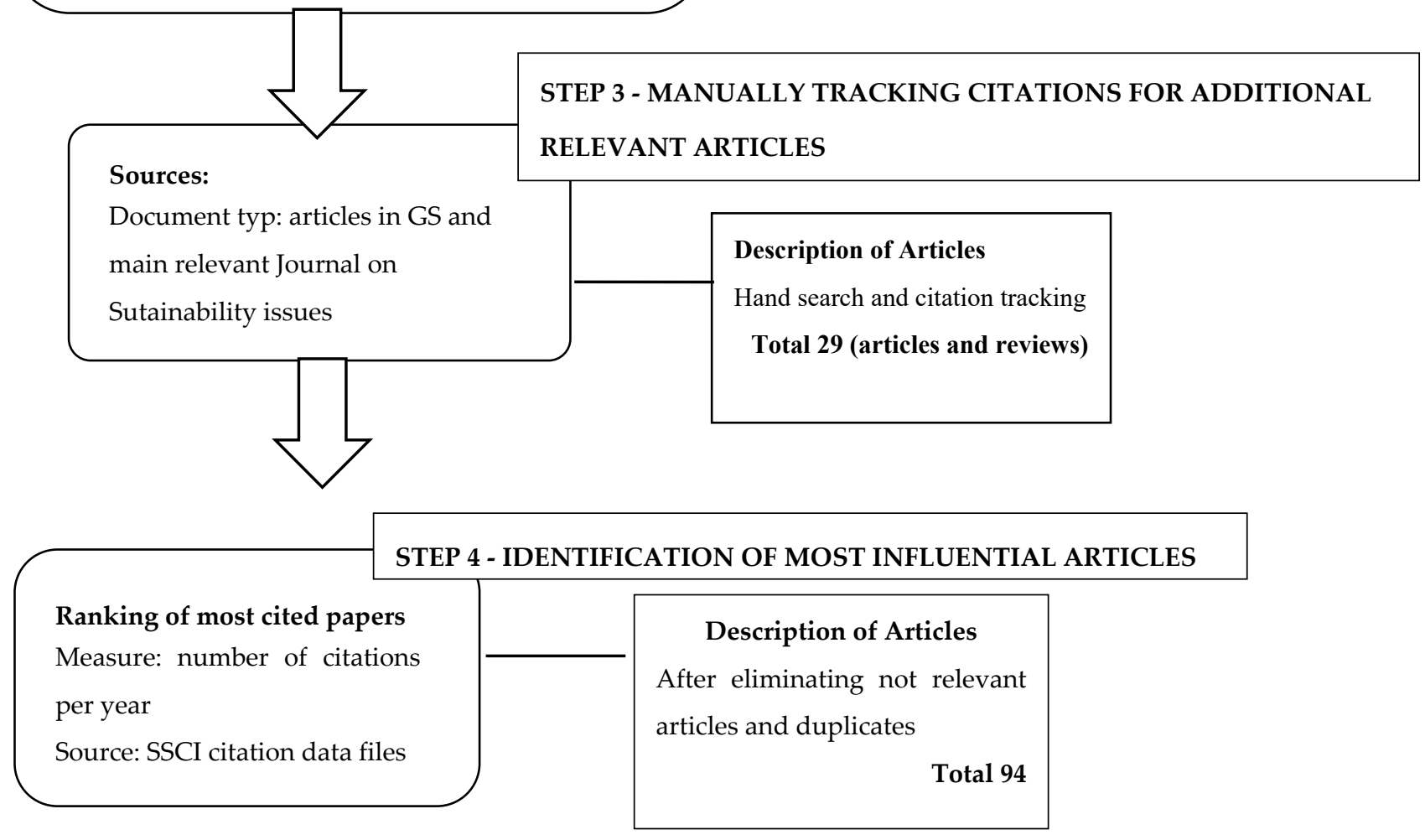

Figure 1. Methodology phases.

These combinations allowed us to gather all the documents about AI in the WEF nexus, including AI in the business models meeting SDGs. Then, considering that WoS and Scholar might exclude some documents relevant for our analysis, we completed the 
data collection by manually researching GS, obtaining 29 other articles. Additionally, the extraction of articles has been completed by manual research on GS following the same procedure and consulting the main journals known to publish articles on AI, business models, the SDGs, and the WEF nexus, such as Journal of Business Research, Journal of Cleaner Production, International Journal of Information Management, Sustainability, Business and Strategy and Environment, Environment, and Development and Sustainability to avoid excluding any relevant reference for our research [16]. To identify the articles on the topics proposed in this study, we selected the following keywords: "artificial intelligence", "water energy and food", "W-E-F nexus", "sustainable development goal", and "business model $^{* \prime}$. A total of 29 documents have been selected.

\subsection{Period of Survey}

We used the manual control provided by default from WoS and Scopus, selecting the time range from 1990 to 2021, as well as in GS.

\subsection{Document Type}

The authors extracted from 320 articles not duplicated in the English language, valid for the study by screening the study through the abstracts and the introduction. We carried out a content analysis of all the abstracts to highlight the correspondence with our research aims, excluding those distant from our issues. All authors executed this activity separately, and after that, they compared their results to guarantee the research's reliability [51].

We studied documents entirely to identify the most relevant research paths with our RQ. All authors have studied the documents separately to highlight the critical and relevant aspects useful for our study. The articles that were not useful for our research and duplicates were removed from the database. All authors compared their own results from the analysis and wrote the sections of this paper. Our database comprises 94 documents: 80 articles (WoS and Scopus) and 14 articles and reviews (GS).

\section{Results}

Following the various steps through which our research has been carried out, our data collection is composed of 94 articles. Most of the articles used quantitative methodologies [52-59] to assess the trade-offs between water and energy, food and energy, or water and food. Case study analysis has often been combined with a quantitative methodology to gain a deeper understanding of WEF in particular contexts or sectors [60-62]. Several reviews have been conducted to systematize the literature on WEF $[8,10,25]$.

Most of the articles did not adopt a specific theoretical lens. Still, several studies $[30,39,41,63,64]$ implicitly refer to stakeholders' theory, evidencing the multi-stakeholder approach required to address the WEF nexus challenge. In this direction, AI technologies can contribute thanks to higher data connectivity and information transparency $[41,43,45]$.

The results evidence that scholars' interest in analyzing the AI and the WEF nexus towards SDG issues started in 2016. This result can be explained by adopting the UN 2030 Agenda in 2015. Moreover, in this context, it is necessary to emphasize that the core of the WEF nexus is three dimensional as it is used from three points of view: as an analytical tool, as a conceptual framework, and for discourse. Thus, firstly, the approach analytically applies qualitative and quantitative methods to recognize the interactions among the WEF resources; secondly, it streamlines an understanding of the WEF relationships to stimulate coherence in policy making and improve sustainable development; thirdly, it is a tool for problem enclosing and stimulating cross-sectoral partnership [65]. Hence, the WEF nexus approach is a pathway for understanding dynamic and composite interrelations between topics linked to water, energy, and food security.

Consequently, it can also be used to observe the performance of the WEF nexus indicators that are associated with SDGs, mainly Goals Zero Hunger, Clean Water and Sanitation, and Affordable and Clean Energy. Therefore, cross-sectoral sustainability indicators can be derived through an advanced and integrated WEF nexus approach. As 
sectoral approaches to resource management often fail to identify and manage cross-sector synergies and trade-offs, they risk significant and undesirable consequences.

The content analysis of the articles in our data collection revealed that most scholars studied the interactions between water, energy, and food sectors from a biophysical and technical perspective. Several of these studies have adopted an agri-food centric model [52-54,66-68], confirming the lack of balance among the three sectors [7]. The role played by technological innovations in addressing the WEF nexus is evident in all the studies analyzed, and AI has been growing in prominence in recent years. Specifically, the water sector has seen AI's implementation to make predictions about rainfall [57] and the future effect of climate change and irrigation intensification [56]. In the agri-food sector, AI has found several ways to be applied, e.g., in horticulture for greenhouse controlling activities [59] or the optimization of fertilizers, pesticides, and irrigation processes by reducing the environmental effects, or in the food production chain for control quality. Technology innovations such as the use of drones in agriculture, remote sensing, precision gene processing in plants, epigenetics, big data and IoT utilizing all types of energy such as smart wind and solar energy efficiently, AI-based applications of robotics, and desalination technology are playing an important role in developing the economy $[52,53,66]$. The application of these technologies has advantages in terms of efficiency and profitability by reducing costs. From a sustainable development perspective, technological innovations are fundamental for companies to compete and create sustainable business models $[15,16,63]$. Some scholars emphasize that AI needs to establish common frameworks, languages, and indicators to measure the environmental cross-sector impacts $[69,70]$ for addressing the WEF nexus. The lack of internationally accepted reporting standards makes it difficult to assess sustainability. The indicators proposed by the literature on sustainability often ignore the interactions between natural resources and cannot evaluate the environmental impact on the whole system. Scholars have proposed several different methods to calculate the trade-offs between energy, land, and water along supply chains. Gerbens-Leenes et al. [57] offer a systemic approach, suggesting three performance indicators: the total land, energy, and water requirement per kilogram of available food. Such models allow companies to compare results with targets and to benchmark a company against others and consumers to compare the environmental effects of various foods. System dynamics models are one of the tools for the simulation and assessment of the system-wide impacts caused by local interventions [71]. Nika et al. [69] developed a novel approach for selecting indicators based on practitioners' views and needs while considering the complex interdependencies of the indicators and determining their importance. They identify 20 circularity indicators for the Water-Energy-Food-Ecosystems nexus, selected and ranked by different stakeholders.

A general framework for introducing AI-based management systems in business models does not emerge from the literature. Veldhuis et al. [60] combine insights from engineering, business, and policy perspectives and explore opportunities and challenges towards a more localized and sustainable food system. They highlight that energy efficiency, water consumption, waste reduction, and carbon footprint may be affected by the scale and location of production activities and potential industrial symbiosis. On the other hand, Wada et al. [61] highlight the need to adopt a multi-stakeholder approach and context-based solutions for more integrated and inclusive development pathways towards SDGs. The WEF model is also considered a multi-centric tool for integrated resource management to provide scientific support for decision makers. However, the multitude of different actors involved often determines the overlap of interests, risks, and jurisdictions, leading to fragmented decision making and suboptimal outcomes.

The use of AI supports people in making complex decision-making processes and finding optimal solutions, thanks to the collection and elaboration of huge amounts of data, evidenced in several studies $[41,58-60,62,64,68]$. However, the research lacks investigations of the performance achieved by business adoption of AI-based solutions, limiting the analysis to natural resource optimization. "The challenge for research is to understand the critical mass of interest based on interactions involving decisions on financing, technology 
choice and leadership that would support effective implementation" [8] (p. 99). The analysis of AI contribution to SDGs' achievement has recently attracted scholars' interests [40,44,45], which highlights the benefits related to their use, mostly lying in the capability to support decision-making processes in using resources and services more efficiently. This is possible thanks to the adoption of several digital technologies, e.g., IoT, big data, and AI, that analyze data collected by remote sensing, geographic information systems (GIS), satellite and weather information-based consultation, real-time monitoring, drones, digital twins, and so forth. These technologies have been applied in agriculture, water, and energy, allowing weather and climate changes to be predicted, water plant functioning to be monitored and managed, energy systems based on renewable energy to be decentralized to ensure food product quality, and so on. Some scholars $[40,44,45]$ highlighted how the smart use of datasets in all industries may foster the achievement of UN 2030 Agenda targets, ensuring consistent energy savings (up to $20 \%$ ), carbon emissions reduction, water use optimization, citizens' well-being, and quality of life improvements (i.e., by applying digital technologies to the health care sector) and improving the resilience of organizations to external changes, such as pandemic events, allowing remote operations and favoring social distancing, and to climate and biodiversity changes, through prediction models. The adoption of AI also includes adverse effects, especially the production of e-waste to be disposed of (i.e., out of working electronic devices) and high financial and knowledge investments. These last items could increase the inequalities among the world population, resulting in a new phenomenon called "digital poverty" [40]. Insufficient attention has been paid to these adverse effects that could severely affect the achievement of SDG 10 (Reduced Inequalities). Ryan et al. [72] develop and validate a framework capable of mapping supply chain data for a participatory WEF nexus and generate a data-informed conversation among stakeholders across state, regional, and local organizations. The use of mobile application software can provide unique opportunities for interconnectivity among the several stakeholders involved in the WEF nexus.

Some scholars $[10,41]$ highlighted how AI and other new tools have been developed to address WEF nexus linkage, allowing the evaluation of trade-offs and synergies. The literature has proposed several innovative methods to help to quantify linkages and interactions among the sectors, most of which use mixed approaches and tools. Interactive data sharing platforms and integrated modelling platforms have been designed specifically to address water, energy, and food interactions [73] and identify the trade-offs among these resources, e.g., [74]. Models are combined in new ways to integrate the nexus's physical, technical, social, and economic components. According to [23], using a combination of methods and selecting the most suitable approach for the context considered can provide a broader and deeper understanding of nexus interactions than the studies that used only one method.

Scholars have developed several tools to identify trade-offs between the nexus and support decision makers in their strategies, some of which have been designed to plan one of the three resources, such as Water Evaluation and Planning (WEAP) and Legacies of Agricultural Pollutants (LEAP), respectively for water and energy resources. In contrast, others have been thought to identify the interconnections between energy, food, and water and estimate the effects that changes in one sector might have on the others. Among these, we found: MuSIASEM (Multi-Scale Integrated Analysis of Societal and Ecosystem Metabolism) [75], CLEWS (Climate, Land, Energy, and Water Strategies), and WEF nexus Tool 2.0 [76]. The WEF nexus Tool 2.0 can identify multiple-level interlinkages and provide sustainable resource management strategies governed by a scenario-base nexus framework. Mosalam and El-Barad [41] have underlined the importance of providing accurate data with realistic reports for investments to help anyone who wants to invest in environmental projects, especially in water, energy, and food projects. They developed a cross-application for sustainable development, including the WEF nexus, that considers the interlinkages between the three resources integrated with a business model or financial study for investment projects. This SD calculator application can estimate the budget required for a 
specific project and report on the sustainability and level of adherence to the WEF nexus. This application opens the space to integrate the WEF nexus in business models effectively.

\section{Discussion and Theoretical Implications}

Our review carried out on the main contributions in the literature about the adoption of AI technologies for addressing the WEF nexus highlights interesting perspectives for the future of the UN 2030 Agenda. The management of interlinkages existing among the several SDGs emerged as one of the challenging issues for achieving the sustainability targets. Scholars have widely investigated the WEF nexus, especially from a biophysical and technical perspective, and many models and tools have been developed to estimate the interconnections existing among the three resources [11]. However, they lack evidence of the socio-technical dimension that analyzes human and AI interactions. Models such as deep learning and neural networks are able to analyze the interactions among thousands of variables. Still, these often operate in isolated systems, whilst the external environment involves the interaction among human, ecological, political, economic, and social systems. The understanding of the economic, environmental, and social effects produced by the human implementation of AI solutions is critical; however, it remains unclear.

Despite the substantial efforts made to identify and quantify the interlinkages between water, energy, and food sectors, there continues to be a wide gap between science and policy making in effectively incorporating the solutions in policy agendas. The distance between "theory" and "practice" seems to be due to several obstacles that have been highlighted by scholars, among which we found: rigid sectoral frameworks, entrenched interests, planning and implementation procedures, lack of information tools, and the ability to support decision-making processes $[7,8,11]$. These barriers call for contextualized multilevel analyses and multi-stakeholder dialogues that consider all variables and interests involved. Many WEF nexus studies developed and applied a specific method, adapting its characteristics to the case studies analyzed.

AI has been identified as the most promising solution to break down the barriers and accelerate the path towards sustainability. AI is considered a technological solution that supports decision-making processes, solves overlapping information issues, and contributes to reaching SDGs $[16,17]$. The collection, elaboration, and analysis of all necessary data are beyond human skills that could consequently undertake sub-optimal decisions or decide not to assume the risk. Thanks to the development of suitable technology, such as AI, it is possible to predict future scenarios, increase organizations' resilience, and evaluate the possible outcomes of alternative solutions $[16,17,40]$. However, AI also highlights adverse effects that have been rarely considered in the articles analyzed. Previous studies $[14,77]$ evidenced that ML models increase data processing speed, but they also increase the risks associated with data hacking. Cybersecurity would require the establishment of effective protocols and policies and specific training and educational programs for the organizations and stakeholders involved. Another adverse effect is that related to machine and technological device waste disposal and to energy consumption related to their functioning [78]. Evaluating only the positive aspects could be detrimental for the achievement of sustainability goals that technology claims to foster. This would require the performance assessment of any intervention, considering the economic, social, and environmental impact [79] produced on all stakeholders, including the impact of AI technologies, as well as other digital technologies.

The analysis of the articles in our data collection highlights that the policy and decision makers lack access to comprehensive tools that include all stakeholders and consider the multi-scale nature and context-dependence of the nexus. Digital platforms have been developed to define and quantify the interconnectivity between water, energy, and food resources and include integrative and holistic management strategies to plan the future allocation of these resources. Moreover, our results evidence that in the literature, the attention to the role of AI for rethinking and redesigning business models for sustainability, including the WEF nexus challenge, is still under-researched. The combination of WEF 
natural resource information with a business model, thanks to the use of AI, may allow considering both technical and financial issues within companies while respecting the WEF approach and contributing to the UN 2030 Agenda [41]. AI applications, with the support of other digital technologies, capable of gathering and elaborating biophysical and technical data with financial data, may support business managers' and external investors' decision-making processes by proposing alternative solutions of investments. A digitalized platform or database can offer alternative solutions that include data on water, energy, and land consumption, and the cost analysis for each solution could support consistently addressing the WEF nexus.

Mosalam and El-Barad [41] propose a comprehensive, integrated platform between a business model and the WEF nexus. This platform uses a web-based knowledge-sharing system to facilitate the cooperation between investors and researchers, supporting the decision-making process. This contribution opens the space to the effective involvement of the private sector in the path of the sustainability challenge. As previous studies $[16,17]$ have highlighted, these technologies would require a complete rethinking of the managerial practices and business models from a sustainability perspective and may increase disparities between developed and developing countries and between well-off people and the poor. AI requires skilled knowledge and financial resources that could benefit some segments of the population over others. As opposed to other analysis methodologies, the WEF nexus places the water-energy-food dimensions on the same level, recognizing the interdependence between resources. The complexity of the nexus is such that it does not allow a single solution. Indeed, an integrated approach is needed to find solutions that ensure the supply of food, water, and energy to a constantly growing population without upsetting the planet's environmental balance. There are no model solutions but rather opportunities to improve food, water, and energy security in a context of sustainability.

The growing pressure on natural resources (also induced by climate change) could contribute to overcoming the current stalemate, providing a cue for new opportunities and paving the way for the integrated planning of all resources and sustainable development goals. While the Millennium Development Goals (MDGs) are aimed at equitable access to natural resources, the SDGs are global challenges that require global solutions. In order to arrive at global solutions, natural resources should be managed collaboratively, taking into due consideration the WEF nexus and not competitively following non-integrated approaches (i.e., Integrated Water Resources Management). Comprehensive and integrated resource planning would be useful for managing trade-offs and could maximize the benefits shared by multiple sectors, thus helping to lower costs and ensure sustainable use of natural resources [64].

Technological innovation, environmental technologies, and research to identify appropriate and adaptive technologies represent an essential component of the nexus approach, which must include structured accompaniment processes, training, technology transfer, and technical assistance in managing technological solutions. If the equivalent of a Kyoto Protocol for the use of food, water, and energy resources globally is conceivable, and if it is necessary to combat land grabbing, water grabbing, and the hoarding of renewable and non-renewable energy sources, then the nexus approach lends itself to establishing itself as a global model for informing development cooperation actions at both the global and local level [80]. In fact, technological innovation, especially that linked to the development of AI, is necessary to increase the productivity of resources, while investments that force development into unsustainable paths should be carefully avoided. It is believed that AI can provide answers to most of the Global Goals, such as food, water, and energy security: that is, AI has come to be an influential aspect of a country's economy. Hence, for the good of one's country and people, a national AI strategy must be developed. If the investments that increase the productivity of water and land were planned in view of the nexus, they would have limited impacts on energy productivity and the environment and, indeed, could potentially increase the overall efficiency of resource management. Furthermore, the adequate integration of climate change in the planning of investments in infrastructures 
could considerably reduce the risk indicated by future climate projections and linked to the physical and economic performances of technologies sensitive to pedoclimatic conditions. A coherent climate change mitigation policy based on local natural heritage and an adaptation strategy that balances the risk of inaction with the risk of inadequate adaptation techniques, accompanied by careful consideration of all the interconnections of the WEF nexus, is essential for setting food, climate, and energy policies suitable for sustainable development.

Our study provides several contributions to academic research on these issues. First, it evidences the existing gap in the literature on the WEF nexus, which has almost exclusively focused on biophysical and technical aspects, excluding the examination of financial, economic, and social issues. Second, our study highlights the scarce knowledge about the WEF nexus application to the UN 2030 Agenda and its potential contributions. Thirdly, our study underlines the need to consider AI's support of WEF nexus management and to generally solve trade-offs and increase the synergies among SDGs, essential for achieving the UN 2030 Agenda. Fourth, our study is unique, evidencing the necessity to consider the combination of AI, business models, the WEF nexus, and SDGs, extending knowledge to economic and social impact assessment of AI-based solutions. This may incentivize the adoption of sustainable solutions to optimize the WEF nexus and SDG interlinkages. This study also provides practical implications for arranging operational practices in the water, energy, and food sectors through the adoption of AI technologies to develop sustainable business models to meet SDGs.

\section{Conclusions, Limitations, and Future Research Perspectives}

Sustainable development (SD) needs to be achieved to harmonize profit, social protection, and environmental respect. In this direction, AI can help businesses, governments, and civil society addresses this challenge, considering all SDGs contemporarily. In line with previous studies [16,17], this research confirms that the role of AI in the development of a sustainable business model for the WEF nexus is currently unexplored in the academic literature. Although scholars have made strong efforts to identify and quantify the interlinkages between water, energy, and food sectors, there continues to be a wide gap between science and policy making in effectively incorporating the solutions in policy agendas. This gap could be reduced through the integration of scientific data and policy needs into inclusive tools that address policy goals and are technically viable from the perspective of sustainable resource utilization.

The frequent occurrence of climatic changes and pandemic events, combined with the continuous growth of the world population, exerts pressure on natural resources. The ability to react and define proper policies and management practices requires a deep understanding of interlinkages existing among resources, multiple governances, and planning mechanisms capable of coordinating all stakeholders. A better understanding of the several ways these resources are interconnected (biophysical, policy, social, and economic) will be possible only through an active dialogue and knowledge exchange among researchers, firms, policymakers, and society. Recent studies [28,41,81] have proposed WEF nexus platforms that integrate the several dimensions and scales of analysis and offer a valid support to decision makers. Hence, in this context, the importance of analyzing the possible interrelationships of the WEF nexus considered was highlighted, therefore not only regarding the coupled synergies between the single elements of the nexus itself. In the end, while environmental models are suitable decision-making tools, seeing them in combination with policy-based and socio-economic models offers a more holistic indication of the ecosystem. Therefore, while each model delivers insight into a single part of the nexus, incorporating the outputs of all the models illustrates several parts of the problem, providing a better representation and making any succeeding decision making more solid. In this way, from a comprehensive integration approach point of view, it is thinkable to say that governance and policy models are, therefore, capable of offering governance frameworks and policy tools that can support improvement in line with planned actions or alleviate possible environmental effects that could be an outcome from a given sequence of actions. Finally, 
identifying appropriate technologies represents an essential component of the nexus approach, which must include structured processes of training and technical assistance in the management of technological solutions. The cultural drift necessary for the successful implementation of digital technologies should not be underestimated: neither the economic nor the social impact that these would produce for single organizations and the system as a whole.

Author Contributions: Conceptualization, A.D.V.; Data curation, G.D.; Formal analysis, G.D., A.D.V. and F.B.; Funding acquisition, A.D.V.; Investigation, D.B.-L.; Methodology, G.D. and A.D.V.; Resources, G.D. and F.B.; Software, G.D.; Supervision, A.D.V.; Validation, D.B.-L. and F.B.; Visualization, G.D., A.D.V. and F.B.; Writing—original draft, G.D. and A.D.V.; Writing—review \& editing, G.D., A.D.V., D.B.-L. and F.B. All authors have read and agreed to the published version of the manuscript.

Funding: This research received no external funding.

Institutional Review Board Statement: Not applicable.

Informed Consent Statement: Not applicable.

Data Availability Statement: A data collection was designed by WoS, Scopus and GS. All documents are in English language. Final Data can be obtained through email at gabriella.damore@uniparthenope.it.

Conflicts of Interest: The authors declare no conflict of interest.

\section{References}

1. Di Vaio, A.; Trujillo, L.; D'Amore, G.; Palladino, R. Water governance models for meeting sustainable development Goals: A structured literature review. Util. Policy 2021, 72, 101255. [CrossRef]

2. $\quad$ Laspidou, C.S.; Mellios, N.K.; Spyropoulou, A.E.; Kofinas, D.T.; Papadopoulou, M.P. Systems thinking on the resource nexus: Modeling and visualization tools to identify critical interlinkages for resilient and sustainable societies and institutions. Sci. Total Environ. 2020, 717, 137264. [CrossRef]

3. Olawuyi, D. Sustainable development and the water-energy-food nexus: Legal challenges and emerging solutions. Environ. Sci. Policy 2020, 103, 1-9. [CrossRef]

4. Hoff, H. Understanding the nexus. In Background Paper for the Bonn 2011 Nexus Conference: The Water, Energy and Food Security Nexus; Stockholm Environment Institute: Stockholm, Sweden, 2011.

5. Stringer, L.C.; Quinn, C.H.; Berman, R.J.; Le, H.T.V.; Msuya, F.E.; Orchard, S.E.; Pezzuti, J.C.B. Combining Nexus and Resilience Thinking in a Novel Framework to Enable More Equitable and Just Outcomes; Sustainability Research Institute Paper No. 193; Sustainability Research Institute: Leeds, UK, 2014; Volume 73.

6. Weitz, N.; Strambo, C.; Kemp-Benedict, E.; Nilsson, M. Closing the governance gaps in the water-energy-food nexus: Insights from integrative governance. Glob. Environ. Chang. 2017, 45, 165-173. [CrossRef]

7. Pahl-Wostl, C. Governance of the water-energy-food security nexus: A multilevel coordination challenge. Environ. Sci. Policy 2019, 92, 356-367. [CrossRef]

8. Kurian, M. The water-energy-food nexus: Trade-offs, thresholds and transdisciplinary approaches to sustainable development. Environ. Sci. Policy 2017, 68, 97-106. [CrossRef]

9. Le Blanc, D. Towards integration at last? The sustainable development goals as a network of targets. Sustain. Dev. 2015, 23, 176-187. [CrossRef]

10. Srigiri, S.R.; Dombrowsky, I. Governance of the water-energy-food nexus for an integrated implementation of the 2030 Agenda: Conceptual and methodological framework for analysis. Discuss. Pap. 2021, 2, 1-28.

11. Simpson, G.B.; Jewitt, G.P. The water-energy-food nexus in the Anthropocene: Moving from 'nexus thinking 'to 'nexus action. Curr. Opin. Environ. Sustain. 2019, 40, 117-123. [CrossRef]

12. Albrecht, T.R.; Crootof, A.; Scott, C.A. The water-energy-food nexus: A systematic review of methods for nexus assessment. Environ. Res. Lett. 2018, 13, 043002. [CrossRef]

13. Silvestre, B.S.; Ţîrcă, D.M. Innovations for sustainable development: Moving toward a sustainable future. J. Clean. Prod. 2019, 208, 325-332. [CrossRef]

14. Nishant, R.; Kennedy, M.; Corbett, J. Artificial intelligence for sustainability: Challenges, opportunities, and a research agenda. Int. J. Infor. Manag. 2020, 53, 102104. [CrossRef]

15. Di Vaio, A.; Hassan, R.; Alavoine, C. Data intelligence and analytics: A bibliometric analysis of human-Artificial intelligence in public sector decision-making effectiveness. Technol. Forecast. Soc. Chang. 2022, 174, 121201. [CrossRef]

16. Di Vaio, A.; Palladino, R.; Hassan, R.; Escobar, O. Artificial intelligence and business models in the sustainable development goals perspective: A systematic literature review. J. Bus. Resear. 2020, 121, 283-314. [CrossRef]

17. Di Vaio, A.; Boccia, F.; Landriani, L.; Palladino, R. Artificial intelligence in the agri-food system: Rethinking sustainable business models in the COVID-19 scenario. Sustainability 2020, 12, 4851. [CrossRef] 
18. Mikalef, P.; Framnes, V.A.; Danielsen, F.; Krogstie, J.; Olsen, D. Big Data Analytics Capability: Antecedents and Business Value. In Proceedings of the Pacific Asia Conference on Information Systems, Langkawi Island, Malaysia, 16-20 July 2017 ; p. 136.

19. Schneider, S.; Leyer, M. Me or information technology? Adoption of artificial intelligence in the delegation of personal strategic decisions. Manag. Dec. Econ. 2019, 40, 223-231. [CrossRef]

20. Bebbington, J.; Unerman, J. Achieving the United Nations Sustainable Development Goals. Account. Audit. Account. J. 2018, 31, 2-24. [CrossRef]

21. Caprani, L. Five Ways the Sustainable Development Goals are Better than the Millennium Development Goals and Why Every Educationalist Should Care. Manag. Educ. 2016, 30, 102-104. [CrossRef]

22. Duan, W.L.; Chen, Y.N.; Zou, S.; Nover, D. Managing the water-climate- food nexus for sustainable development in Turkmenistan. J. Clean. Prod. 2019, 20, 220. [CrossRef]

23. Dwivedi, Y.K.; Hughes, L.; Ismagilova, E.; Aarts, G.; Coombs, C.; Crick, T.; Duan, Y.; Dwivedi, R.; Edwards, J.; Eirug, A. Artificial Intelligence (AI): Multidisciplinary perspectives on emerging challenges, opportunities, and agenda for research, practice and policy. Int. J. Infor. Manag. 2021, 57, 101994. [CrossRef]

24. Benson, D.; Gain, A.K.; Rouillard, J.J. Water governance in a comparative perspective: From IWRM to a'nexus' approach? Water Altern. 2015, 8, 756-773.

25. Endo, A.; Tsurita, I.; Burnett, K.; Orencio, P.M. A review of the current state of research on the water, energy, and food nexus. J. Hydrol. Reg. Stud. 2017, 11, 20-30. [CrossRef]

26. DiMaggio, P.J.; Powell, W.W. The iron cage revisited: Institutional isomorphism and collective rationality in organizational fields. Am. Sociol. Rev. 1983, 48, 147-160. [CrossRef]

27. Urbinatti, A.M.; Benites-Lazaro, L.L.; Carvalho, C.M.D.; Giatti, L.L. The conceptual basis of water-energy-food nexus governance: Systematic literature review using network and discourse analysis. J. Integr. Environ. Sci. 2020, 17, 21-43. [CrossRef]

28. Ghodsvali, M.; Krishnamurthy, S.; de Vries, B. Review of transdisciplinary approaches to food-water-energy nexus: A guide towards sustainable development. Environ. Sci. Policy 2019, 101, 266-278. [CrossRef]

29. Liu, J.; Yang, H.; Cudennec, C.; Gain, A.K.; Hoff, H.; Lawford, R.; Qi, J.; de Strasser, L.; Yillia, P.T.; Zheng, C. Challenges in operationalizing the water-energy-food nexus. Hydrol. Sci. J. 2017, 62, 1714-1720. [CrossRef]

30. Mohtar, R.H.; Daher, B. Water-energy-food nexus framework for facilitating multi-stakeholder dialogue. Water Int. 2016, 41, 655-661. [CrossRef]

31. Bonn Conference. Messages from the Bonn2011 Conference: The Water, Energy and Food Security Nexus—Solutions for a Green Economy. In The Water, Energy and Food Security Nexus—Solutions for a Green Economy, Bonn; Stockholm Environment Institute: Stockholm Sweden, 2011.

32. Freeman, R.E. Stakeholder Management: Framework and Philosophy; Pitman: Mansfield, MA, USA, 1984.

33. Parmar, B.L.; Freeman, R.E.; Harrison, J.S.; Wicks, A.C.; Purnell, L.; De Colle, S. Stakeholder theory: The state of the art. Acad. Manag. Ann. 2010, 4, 403-445. [CrossRef]

34. Bergendahl, J.A.; Sarkis, J.; Timko, M.T. Transdisciplinarity and the food energy and water nexus: Ecological modernization and supply chain sustainability perspectives. Res. Conserv. Recycl. 2018, 133, 309-319. [CrossRef]

35. Villamor, G.B.; Griffith, D.L.; Kliskey, A.; Alessa, L. Integrating public/local and scientific knowledge in model development for food-energy-water systems. In Proceedings of the 9th International Congress on Environmental Modelling and Software, Ft. Collins, CO, USA, 24-28 June 2018.

36. Kaplan, A.; Haenlein, M. Siri, Siri, in my hand: Who's the fairest in the land? On the interpretations, illustrations, and implications of artificial intelligence. Bus. Horiz. 2019, 62, 15-25. [CrossRef]

37. Kahneman, D.; Rosenfield, A.M.; Gandhi, L.; Blaser, T. Noise. Harv. Bus. Rev. 2016, 38-46.

38. Tsui, E. Exploring the KM toolbox. Knowl. Manag. 2000, 4, 11-14.

39. Schroeder, P.; Anggraeni, K.; Weber, U. The relevance of circular economy practices to the sustainable development goals. J. Ind. Ecol. 2019, 23, 77-95. [CrossRef]

40. Mondejar, M.E.; Avtar, R.; Diaz, H.L.B.; Dubey, R.K.; Esteban, J.; Gómez-Morales, A.; Hallam, B.; Mbungu, N.T.; Okolo, C.C.; Prasad, K.A.; et al. Digitalization to achieve sustainable development goals: Steps towards a Smart Green Planet. Sci. Total Environ. 2021, 794, 148539. [CrossRef]

41. Mosalam, H.A.; El-Barad, M. Design of an integration platform between the water-energy nexus and a business model applied for sustainable development. Water Sci. Technol. 2020, 81, 1398-1405. [CrossRef] [PubMed]

42. Morris, M.; Schindehutte, M.; Allen, J. The entrepreneur's business model: Toward a unified perspective. J. Bus. Res. 2005, 58, 726-735. [CrossRef]

43. Dirican, C. The Effects of Technological Development and Artificial Intelligence Studies on Marketing. J. Manag. Market. Logist. 2015, 2

44. Palomares, I.; Martínez-Cámara, E.; Montes, R.; García-Moral, P.; Chiachio, M.; Chiachio, J.; Alonso, S.; Melero, F.J.; Molina, D.; Fernández, B.; et al. A panoramic view and swot analysis of artificial intelligence for achieving the sustainable development goals by 2030: Progress and prospects. Appl. Intell. 2021, 51, 6497-6527. [CrossRef]

45. Vinuesa, R.; Azizpour, H.; Leite, I.; Balaam, M.; Dignum, V.; Domisch, S.; Felländer, A.; Langhans, S.D.; Tegmark, M.; Nerini, F.F. The role of artificial intelligence in achieving the Sustainable Development Goals. Nat. Commun. 2020, 11, 233. [CrossRef] 
46. Sachs, J.D.; Schmidt-Traub, G.; Mazzucato, M.; Messner, D.; Nakicenovic, N.; Rockström, J. Six Transformations to achieve the Sustainable Development Goals. Nat. Sustain. 2019, 2, 805-814. [CrossRef]

47. Snyder, H. Literature review as a research methodology: An overview and guidelines. J. Bus. Res. 2019, 104, 333-339. [CrossRef]

48. Braun, V.; Clarke, V. Using thematic analysis in psychology. Qual. Res. Psychol. 2006, 3, 77-101. [CrossRef]

49. Hicks, D.; Wang, J. Coverage and overlap of the new social sciences and humanities journal lists. J. Am. Soc. Inf. Sci. Technol. 2011, 62, 284-294. [CrossRef]

50. Zupic, I.; Čater, T. Bibliometric methods in management and organization. Organ. Res. Methods 2015, 18, 429-472. [CrossRef]

51. Krippendorff, K. Validity in Content Analysis; Sage Publishing: New York, NY, USA, 1980.

52. Lal, R. The role of industry and the private sector in promoting the 4 per 1000 initiative and other negative emission technologies. Geoderma 2020, 378, 114613. [CrossRef]

53. Virnodkar, S.S.; Pachghare, V.K.; Patil, V.C.; Jha, S.K. Remote sensing and machine learning for crop water stress determination in various crops: A critical review. Precis. Agric. 2020, 21, 1121-1155. [CrossRef]

54. Sampath, P.V.; Jagadeesh, G.S.; Bahinipati, C.S. Sustainable Intensification of Agriculture in the Context of the COVID-19 Pandemic: Prospects for the Future. Water 2020, 10, 2738. [CrossRef]

55. Palanichamy, M.; Sankaralingam, R. Narayanasamy. Statistical Studies on Rainfall and Time-based Deviations in Precipitation Trends in Vaigai River Basin, TN State, India. Indian J. Geo-Mar. Sci. 2020, 49, 15-23.

56. Sishodia, R.P.; Shukla, S.; Wani, S.P.; Graham, W.D.; Jones, J.W. Future irrigation expansion outweigh groundwater recharge gains from climate change in semi-arid India. Sci. Total Environ. 2018, 635, 725-740. [CrossRef]

57. Gerbens-Leenes, P.W.; Moll, H.C.; Uiterkamp, A.J.M.S. Design and development of a measuring method for environmental sustainability in food production systems. Ecol. Econ. 2003, 46, 231-248. [CrossRef]

58. Govindan, R.; Al-Ansari, T. Computational decision framework for enhancing resilience of the energy, water and food nexus in risky environments. Renew. Sustain. Energy Rev. 2019, 112, 653-668. [CrossRef]

59. Zhou, Y.L.; Chang, L.C.; Uen, T.S.; Guo, S.L.; Xu, C.Y.; Chang, F.J. Prospect for small-hydropower installation settled upon optimal water allocation: An action to stimulate synergies of water-food-energy nexus. Appl. Energy 2019, 238, 668-682. [CrossRef]

60. Veldhuis, A.J.; Glover, J.; Bradley, D.; Behzadian, K.; López-Avilés, A.; Cottee, J.; Downing, C.; Ingram, J.; Leach, M.; Farmani, R.; et al. Re-distributed manufacturing and the food-water-energy nexus: Opportunities and challenges. Prod. Plan. Contr. 2019, 30, 593-609. [CrossRef]

61. Wada, Y.; Vinca, A.; Parkinson, S.; Willaarts, B.A.; Magnuszewski, P.; Mochizuki, J.; Mayor, B.; Wang, Y.P.; Burek, P.; Byers, E.; et al. Co-designing Indus Water-Energy-Land Futures. One Earth 2019, 1, 185-194. [CrossRef]

62. Camaréna, S. Engaging with Artificial Intelligence (AI) with a Bottom-Up Approach for the Purpose of Sustainability: Victorian Farmers Market Association, Melbourne Australia. Sustainability 2021, 13, 9314. [CrossRef]

63. de Sousa Jabbour, A.B.L.; Luiz, J.V.R.; Luiz, O.R.; Jabbour, C.J.C.; Ndubisi, N.O.; de Oliveira, J.H.C.; Junior, F.H. Circular economy business models and operations management. J. Clean. Prod. 2019, 235, 1525-1539. [CrossRef]

64. Uen, T.S.; Chang, F.J.; Zhou, Y.L.; Tsai, W.P. Exploring synergistic benefits of Water-Food-Energy Nexus through multi-objective reservoir optimization schemes. Sci. Total Environ. 2018, 633, 341-351. [CrossRef]

65. Nhamo, L.; Mabhaudhi, T.; Mpandeli, S.; Dickens, C.; Nhemachena, C.; Senzanje, A.; Naidoo, D.; Liphadzi, S.; Modi, A.T. An integrative analytical model for the water-energy-food nexus: South Africa case study. Environ. Sci. Policy 2020, 109, 15-24. [CrossRef]

66. Goel, R.K.; Yadav, C.S.; Vishnoi, S.; Rastogi, R. Smart agriculture-Urgent need of the day in developing countries. Sustain. Comput.-Inform. Syst. 2021, 30, 100512. [CrossRef]

67. Resende, R.T.; Kuki, K.N.; Correa, T.R.; Zaidan, U.R.; Mota, P.H.S.; Telles, L.A.A.; Gonzales, D.G.E.; Motoike, S.Y.; Resende, M.D.V.; Leite, H.G.; et al. Data-based agroecological zoning of Acrocomia aculeata: GIS modeling and ecophysiological aspects into a Brazilian representative occurrence area. Ind. Crops Prod. 2020, 154, 112749. [CrossRef]

68. Hemming, S.; de Zwart, F.; Elings, A.; Righini, I.; Petropoulou, A. Remote control of greenhouse vegetable production with artificial intelligence-Greenhouse climate, irrigation, and crop production. Sensors 2019, 19, 1807. [CrossRef] [PubMed]

69. Nika, C.E.; Exposito, A.; Kisser, J.; Bertino, G.; Oral, H.V.; Dehghanian, K.; Vasilaki, V.; Iacovidou, E.; Fatone, F.; Atanasova, N.; et al. Validating Circular Performance Indicators: The Interface between Circular Economy and Stakeholders. Water 2021, 13, 2198. [CrossRef]

70. Das, K. Integrating Lean, Green, and Resilience Criteria in a Sustainable Food Supply Chain Planning Model. Int. J. Math. Eng. Manag. Sci. 2019, 4, 259-275. [CrossRef]

71. Purwanto, A.; Sušnik, J.; Suryadi, F.X.; de Fraiture, C. Water-energy-food nexus: Critical review, practical applications, and prospects for future research. Sustainability 2021, 13, 1919. [CrossRef]

72. Ryan, S.M.; Roberts, E.; Hibbett, E.; Bloom, N.; Haden, C.; Rushforth, R.R.; Pfeiffer, K.; Ruddell, B.L. The FEWSION for Community Resilience (F4R) Process: Building Local Technical and Social Capacity for Critical Supply Chain Resilience. Front. Environ. Sci. 2021, 6, 601220. [CrossRef]

73. Bekchanov, M.; Lamers, J. The effect of energy constraints on water allocation decisions: The elaboration and application of a System-Wide Economic-Water-Energy Model (SEWEM). Water 2016, 8, 253. [CrossRef]

74. Perrone, D.; Hornberger, G. Frontiers of the food-energy-water trilemma: Sri Lanka as a microcosm of trade-offs. Environ. Res. Lett. 2016, 11, 014005. [CrossRef] 
75. Giampietro, M.; Mayumi, K.; Martín, J.R. Multi-Scale Integrated Analysis of Societal and Ecosystem Metabolism (MUSIASEM): An outline of rationale and theory. Energy 2008, 34, 313-322. [CrossRef]

76. Daher, B.; Mohtar, R.H. Water-energy-food (WEF) Nexus Tool 2.0: Guiding integrative resource planning and decision-making. Water Int. 2015, 40, 748-771. [CrossRef]

77. Denning, D.E. Is Quantum Computing a Cybersecurity Threat? Although quantum computers currently don't have enough processing power to break encryption keys, future versions might. Am. Sci. 2019, 107, 83-86. [CrossRef]

78. Hao, K. Training a Single AI Model Can Emit as much Carbon as Five Cars in Their Lifetimes. Available online: https:// www.technologyreview.com/s /613630/training-a-single-ai-model-can-emit-as-much-carbon-as-five-cars-in-their-lifetimes / (accessed on 8 November 2021).

79. Sarnacchiaro, P.; Boccia, F. Some remarks on measurement models in the structural equation model: An application for socially responsible food consumption. J. Appl. Stat. 2018, 45, 1193-1208. [CrossRef]

80. Malagó, A.; Comero, S.; Bouraoui, F.; Kazezyılmaz-Alhan, C.M.; Gawlik, B.M.; Easton, P.; Laspidou, C. An analytical framework to assess SDG targets within the context of WEFE nexus in the Mediterranean region. Resour. Conserv. Recycl. 2021, $164,105205$. [CrossRef] [PubMed]

81. Lawford, R.G. A design for a data and information service to address the knowledge needs of the Water-Energy-Food (WEF) Nexus and strategies to facilitate its implementation. Front. Environ. Sci. 2019, 7, 56. [CrossRef] 